\title{
IoT Tabanlı Platform ile Gerçek Zamanlı İç Ortam Hava Kalitesi İzleme Sistemi
}

\author{
Hakan ÜÇGÜN ${ }^{1 *}$, Fatmanur GÖMBECİ², Uğur YÜZGEÇ3 ${ }^{3}$ Nesibe YALÇIN ${ }^{4}$ \\ Geliş / Received: 02/05/2020 \\ Revize / Revised: 11/06/2020 \\ Kabul / Accepted: 12/06/2020
}

\section{ÖZ}

Hava kirliliği, günümüzde karşılaştı̆̆ımız en büyük problemlerden bir tanesidir. İnsan sağlığı, iklim ve ekosistem üzerinde olumsuz etkilere yol açan hava kirliliğinin artmasında, atmosferdeki kirleticilerin miktarlarındaki artışın yanı sıra iç ortamlardaki hava kalitesininde katkısı olduğu bir gerçektir. Günlük yaşantısının büyük bir kısmını kapalı iç ortamlarda (evlerde, ofislerde, okullarda, hastanelerde, alışveriş merkezlerinde vb.) geçiren insanlar, ortamın havasındaki zararlı gazlardan ve partikül maddelerden etkilenmekte ve sağlık sorunları yaşayabilmektedir. Bu tarz ortamlardaki yaşam standartlarının insan yaşamı için optimum değerlerde tutulması ve insan sağglı̆ı̆ı tehdit edebilecek faktörlerin belirlenerek ortadan kaldırılması ya da etkilerinin azaltılması gerekmektedir. Teknolojik gelişmeler sayesinde ortamın hava kalitesinin belirlendiği sistemler ile bu tarz sorunların ortadan kaldırılması mümkündür. Bu çalışma kapsamında, IoT tabanlı iç ortam hava kalitesi izleme sistemi gerçekleştirilmiştir. Oluşturulan sistem içerisinde Raspberry Pi 3 kontrol kartı, sıcaklık, nem, gaz ve ışık sensörleri kullanılmıştır. Sensörler aracılığıyla alınan iç ortam verileri, kontrol kartı aracılığıyla işlenerek elde edilmiş ve veri tabanına kaydedilmiştir. Hazırlanan web arayüzü ile iç ortamdaki yaşam koşullarına ilişkin bilgiler anlık olarak takip edilebilmektedir. Geliştirilen hava kalitesi formülü kullanılarak iç ortam hava kalitesi hesaplanarak kullanıcılara aktarılmaktadır. Taşınabilir donanım platformu ile herhangi bir iç ortamın hava kalitesinin tespit edilmesi sağlanmaktadır.

Anahtar Kelimeler- İç Ortam Hava Kalitesi, Gerçek Zamanlı İzleme, Nesnelerin İnterneti, Raspberry Pi, Sensör Teknolojileri

\footnotetext{
1*Sorumlu yazar iletişim: hakan.ucgun@bilecik.edu.tr (https://orcid.org/0000-0002-9448-0679)

Bilgisayar Mühendisliği, Bilecik Şeyh Edebali Üniversitesi, Gülümbe Kampüsü, Merkez, Bilecik

2illetişim: fatmanurg.1997@gmail.com (https://orcid.org/0000-0002-3375-3557)

3̇letişim: ugur.yuzgec@bilecik.edu.tr (https://orcid.org/0000-0002-5364-6265)

Bilgisayar Mühendisliği, Bilecik Șeyh Edebali Üniversitesi, Gülümbe Kampüsü, Merkez,

4İletişim: nyalcin@bartin.edu.tr (https://orcid.org/0000-0003-0324-9111)

Bilgisayar Mühendisliği, Bartın Üniversitesi, Kutlubey Yazıcılar Kampüsü, Merkez,
} 


\title{
Real Time Indoor Air Quality Monitoring System with Platform based on IoT
}

\begin{abstract}
Air pollution is one of the major problems in the world we face today. Air pollution, which has negative effects on human health, climate and ecosystem, increases due to the increase in the amounts of pollutants in the atmosphere and also indoor air pollution. People who spend most of their daily life indoor environments (e.g. homes, offices, schools, hospitals, shopping centers) are affected by harmful gases and particulates in the environment and may have health problems. Living standards in such environments should be kept at optimum values for human life, the factors that may threaten human health should be eliminated, and their effects should be reduced. Thanks to technological developments, it is possible to eliminate such problems with the systems where air quality is determined. Within the scope of this study, IoT based indoor air quality monitoring system has been developed. In the system, Raspberry Pi 3 controller card, temperature, humidity, gas and light sensors are used in the system. The environment data from the sensors has been processed by the control card and then saved to the database. Information about living conditions in the indoor environment can be monitored instantly via web user interface Indoor air quality is calculated using the developed air quality formula and presented to the users. The portable hardware platform enables the determination of air quality in any indoor environment.
\end{abstract}

Keywords- Indoor Air Quality, Real Time Monitoring, Internet of Things, Raspberry Pi, Sensor Technologies 


\section{GİRIȘ}

Nesnelerin interneti (IoT, Internet of Things) teknolojisi, gerçek dünyadaki nesnelerin internet aracılığıyla birbirleri ile haberleşmesini sağlamaktadır [1]. Bu teknoloji ile cihazlar, insan müdahalesi olmadan birbirlerini algılayabilir, tanımlayabilir, iletişim kurarak bilgi transferinde bulunabilir [2]. Genel olarak, veri toplamak ya da veri transferi yapmak için donanım bileşenleri, sensörler, aktüatörler, akıllı cihazlar ve yazılımlar içermektedirler. İç ve dış ortam hava kalitesinin izlenmesi, ev izleme ve güvenlik sistemleri, yaşlı bakım sistemleri, binalarda enerji yönetimi ve mikro iklim izleme sistemleri [3] gibi pek çok IoT tabanlı uygulama günümüzde kullanılmaktadır.

Hava kirliliği atmosferdeki yabancı maddelerin, canlı yaşamına zarar verecek derecede yoğunluğa ulaşması ve ekolojik dengeye zarar vermesi olarak tanımlanabilir. Hava kirliliği, insan hayatını ciddi bir şekilde etkilemekte ve sürekli maruz kalındığında ciddi hastalıklara sebep olabilmektedir [4]. 2019 yılındaki hava kirliliği, sağlık için en büyük çevresel risk olarak kabul edilmiştir. Hava kirliliği, biyokütle yakımı, araç ve fabrikaların kontrolsüz CO yayması, trafik yoğunluğu gibi durumlar sebebiyle artış göstermiştir [5].

Hava kirliliği, faaliyetlerin gerçekleştiği yere bağlı olarak iki gruba ayrılabilir: dış ortam hava kirliliği, tüm atmosferi ve ötesini kapsayan açık bir ortama ilişkin kirlenme iken; iç ortam hava kirliliği, evler, ofisler ve diğer kapalı alanlardaki kirlenmedir [6]. Pek çok insan dış ortamdaki hava kalitesinin sağlıkları için daha önemli olduğunu düşünürken, iç ortamlardaki hava kirliliği ile ilgili potansiyel risklerden habersizdir [7]. Çevre Koruma Ajansı (Environmental Protection Agency, EPA), kirletici seviyeleri kıyasladığında iç ortamların dış ortamlara göre 2 ila 5 kat daha fazla tehlikeli olduğunu söylemektedir [8]. İç ortam kirleticileri, temizlik ürünleri, yalıtım malzemeleri, mobilyalar, ofis ekipmanları gibi kapalı ortamlarda bulunan emisyon kaynaklarından ve solunum, sigara içme, 1sıtma, yemek pişirme, gibi iç ortam etkinliklerinden meydana gelmektedir [7].

İç ortam hava kalitesi (Indoor Air Quality, IAQ) konusu, son y1llarda artan hava kirliliğinin önemli sağglık sorunlarına yol açması nedeniyle büyük ilgi görmektedir. Kapalı ortamlardaki kimyasal maddeler, uçucu organik bileşenler, yemek ve çöp kokuları gibi etmenler hastalıklara sebebiyet vermektedir [9]. İnsanlar, günümüz koşullarında gün içerisinde uzun süre kapalı ortamlarda bulunmaktadır. Bu sebeple, iç ortamlardaki hava kalitesinin insan sağlığına doğrudan etki ettiği rahatlıkla söylenilebilir [10]. IAQ, insanların sağlığı, rahatlığı ve konforu yanında verimliliğini de etkilediği için bu ortamların sürekli gözetlenmesi ve temizlenmesi gerekmektedir. İç ortamların hava kalitesini gözlemlemek ve kontrol etmek amacıyla, iç ortam izleme sistemlerine ihtiyaç duyulmaktadır. Bu izleme sistemleri ile özellikle çocuklar, yaşlılar ve hastalar için konforlu ve sağlıklı bir ortam sunulabilmektedir.

Bu çalışma kapsamında, iç ortamlardaki hava kalitesinde meydana gelen değişiklikleri takip etmek amacıyla IoT tabanlı bir izleme sistemi gerçekleştirilmiştir. Sistem içerisindeki dijital ve analog sensörlerden (sıcaklık ve nem, gaz, ışık) alınan ortam verilerinin kontrol kartı aracılığıyla işlenmesiyle iç ortamdaki hava kalitesine yönelik değerler elde edilmiştir. Sensör verileri ve hesaplanan IAQ değeri, Wi-Fi ağı üzerinden veri tabanına kaydedilmiştir. Hazırlanan web arayüzü ile veri tabanındaki veriler yazılan web servisler aracılığıyla alınmakta ve kullanıcıların grafiksel ve sayısal olarak IAQ verilerini izleyebilmesi sağlanmaktadır.

\section{II. İÇ ORTAM HAVA KALITESİ VE YAPILAN ÇALIŞMALAR}

Hava kalitesi bilinci, özellikle sağlık ve yaşam konforu açısından dünya genelinde artmaktadır. Günümüzde insanlar yaşamlarının yaklaşık \%90'ını iç ortamlarda geçirmektedir. İç ortamlardaki hava kalitesinin kötü olması, hasta bina sendromu gibi ciddi hastalıklara neden olabilmekte ve giderek artan küresel bir sorun haline gelmektedir [11]. İç hava kalitesi, kapalı ortamlardaki havanın kalitesini belirlemek için kullanılan bir göstergedir ve ortamda bulunan insanların sağlığını, performansını ve konforunu etkileyen ortama ilişkin kirletici seviyeleri, sıcaklık ve nem değerleri, aydınlatma miktarı ile gürültü seviyesi ile ilgilidir [12].

İç ortamlardaki hava kalitesinin izlenmesi ve kontrol edilmesine yönelik çalışmalara bakıldığında, Ha ve arkadaşları [13], gerçek zamanlı sensör verilerini kullanarak IAQ indeksi ve nem indeksini gelişmiş bir iç ortam hava kalitesi indeksinde birleştiren bir hava kalitesi yönetim sistemi önermiştir. İç ortamdaki hava kirletici seviyeleri, bir waspmote sensör ağı ile ölçülürken, hava kalitesi ve nem indeksi verileri, genişletilmiş bir kesirli sıralı Kalman filtresi kullanılarak birbirine bağlanmıştır. Çalışma için bir test merkezi olarak bir ofis binası 


\begin{tabular}{|c|c|c|}
\hline & $\begin{array}{l}\text { BŞEÜ Fen Bilimleri Dergisi } \\
7(1), 370-381,2020\end{array}$ & $\begin{array}{r}\text { BSEU Journal of Science } \\
\text { DOI: } 10.35193 / \text { bseufbd.730919 }\end{array}$ \\
\hline ERS & & 8-7575 (http://dergipark.gov.tr/bseufbd) \\
\hline
\end{tabular}

seçilmiştir. Ofis ortamındaki hidrojen, amonyak, etanol, hidrojen sülfür, karbonmonoksit, karbondioksit ve oksijen değerleri ile sıcaklık ve nem parametreleri ile ilgili veriler toplanmıştır. Jo ve arkadaşları [14], iç mekânlardaki hava kalitesini izlemek amacıyla IoT ve bulut bilişim teknolojisine dayalı "Smart-Air" isimli bir cihaz geliştirmişlerdir. Cihaz ile iç ortamlardaki hava kalitesini her zaman ve her yerde izleyebilmek mümkündür. Cihaz ile ortamdaki aerosol, VOC, CO, CO2 ve sıcaklık-nem konsantrasyonunu ölçülmekte ve LTE modem üzerinde veriler web sunucusuna aktarılmaktadır. Le ve arkadaşları [15], Vietnam Hanoi'deki ilköğretim okulları içerisindeki sınıflarda bulunan havanın kalitesinin ölçümü ve izlenmesine yönelik bir sistem geliştirmişlerdir. Çalışmanın sonucu olarak, okullardaki ana hava kalitesi sorununun özellikle PM2.5 olmak üzere partiküler konular olduğu görülmüş̧ür. Marques ve arkadaşları [16], IoT mimarisine dayalı ortamdaki karbondioksit $\left(\mathrm{CO}_{2}\right)$ miktarının izlenmesini sağlayan bir sistem geliştirmişlerdir. Sistem içerisinde ESP8266 modülü ve $\mathrm{CO}_{2}$ sensörü kullanmış ve sensör verilerini, veri tabanında depolanmıştır. Hazırlanan iAirCO2 uygulaması ile web ve mobil platformlar üzerinden ortamdaki CO2 miktarının grafiksel olarak izlenmesi sağlanmıştır. Sung ve arkadaşları [17], insanların iç ortamlardaki termal konforunu belirlemek için IoT mimarisi aracılığıyla bir iç ortam termal konfor çevre izleme sistemi geliştirmiştir. Sistemde, Arduino Uno mikro denetleyicisi kullanılarak alınan sensör verileri ESP8266 modülü ile kablosuz olarak veri tabanına kaydedilmiştir. Verilerin izlenmesi ve ortamın kontrol edilmesi için bilgisayar ortamında C\# dili ile arayüz hazırlanmıştır. Çalışma sonrasında, termal konfor ve enerji tasarrufu sağlanmıştır. Tiele ve arkadaşları [18], iç ortam kalitesi için düşük maliyetli, taşınabilir bir izleme sistemini tasarlamış ve geliştirmişlerdir. Geliştirilen sistem ile iç ortamlardaki sıcaklık, nem, $\mathrm{PM}_{2.5}, \mathrm{PM}_{10}, \mathrm{CO}, \mathrm{CO}_{2}$, aydınlatma ve ses seviyelerinin izlenmesi sağlanmıştır. Sistemin kullanılabilirliğini kontrol etmek için tipik bir iç mekân çalışma ortamı ve dış mekânlarda çeşitli ortamlarda deneyler yapılmıştır. Salamone ve arkadaşları [19], düşük maliyetli sensörler ve açık kaynaklı donanım ve yazılım kullanarak sınırlı bir alandaki iç ortam kalitesini ölçmeyi amaçlayan bir cihaz geliştirmişlerdir. Önerilen nano Çevresel İzleme Sistemi (nEMoS) cihazı, bir bakımevindeki ve ofisteki termal konforu değerlendirmek için kullanılmış ve iyi bir güvenilirliğe sahip olduğu görülmüştür. Zhao ve arkadaşları [20], yeşil çatıların simülasyonu için kullanılan bir prototip rüzgar tüneline dayanan kablosuz sensör ağları (WSN) sistemi geliştirilmesine yönelik bir sistem sunmuşlardır. PM $_{2.5}$, rüzgâr hızı, sıcaklık ve bağıl nem konsantrasyonunun aynı anda elde edilmiş ve kullanıcı web sitesi üzerinden gerçek zamanlı olarak izlenmiştir. Çalışmanın sonuçları, rüzgâr tüneli modülünün ve sensör ağının güvenilirliğini doğrulamıştır. Zhao ve arkadaşları [21], ileri IoT tekniklerini kullanarak bir iç ortam hava kalitesi detektörü (IAQD) geliştirmişlerdir. IAQD, gerçek zamanlı olarak sıcaklık, nem, $\mathrm{PM}_{2.5}, \mathrm{CO}_{2}$ ve formaldehit parametrelerini tespit edebilmektedir. Farklı uygulama senaryolarının ihtiyaçları için, RS485, LoRa, WiFi, GPRS ve NB-IoT gibi çoklu iletişim arayüzleri kullanılmıştır. Deneyler yapılmış ve istatistiksel analiz sonuçları, önerilen IAQ sisteminin güvenilirliğini ve yüksek performanslı olduğunu göstermektedir. Literatür taraması sonucunda elde edilen çalışmaların karşılaştırmalı analizi, Tablo 1'de verilmiştir.

Tablo 1. Hava İstasyonlarının Karşılaştırmalı Analizi

\begin{tabular}{|c|c|c|c|c|c|c|}
\hline Ref. & İşlemci & Ortam Parametreleri & Mimari & Bağlantı & $\begin{array}{c}\text { Düşük } \\
\text { Maliyet }\end{array}$ & Veri Erişimi \\
\hline [13] & $\begin{array}{l}\text { ATmega1281 } \\
\text { (Waspmote) }\end{array}$ & $\begin{array}{c}\mathrm{CO}, \mathrm{CO}_{2} \text {, Formaldehit, } \mathrm{NO}_{2}, \mathrm{O}_{3}, \mathrm{SO}_{2}, \mathrm{PM}_{2.5} \\
\text { VOC, Sicaklık, Bağıl Nem }\end{array}$ & IoT/WSN & Wi-Fi & $\mathrm{X}$ & Web \\
\hline [14] & $\begin{array}{l}\text { ARM - STM } \\
\text { 32F407IG }\end{array}$ & $\begin{array}{c}\text { Toz, VOC, } \mathrm{CO}, \mathrm{CO}_{2}, \\
\text { Sicaklik, Nem }\end{array}$ & IoT & $\begin{array}{l}\text { LTE } \\
\text { modem }\end{array}$ & $\mathrm{X}$ & Web/Mobil \\
\hline [15] & - & $\mathrm{CO}_{2}, \mathrm{NO}_{2}, \mathrm{PM}_{2.5}, \mathrm{PM}_{10}, \mathrm{VOC}$ & Kablolu & Kablolu & $\mathrm{X}$ & Monitör \\
\hline [16] & $\begin{array}{c}\text { Tensilica LX6 } \\
\text { (SparkFun ESP32) }\end{array}$ & $\mathrm{CO}_{2}$ & IoT & Kablolu & $\sqrt{ }$ & $\begin{array}{l}\text { ThingSpeak } \\
\text { Server }\end{array}$ \\
\hline [17] & Arduino & Aerosol, $\mathrm{CO}_{2}$, Sıcaklık, Nem, Rüzgâr Hızı & IoT & Wi-Fi & $\mathrm{X}$ & PC \\
\hline [18] & $\begin{array}{l}\text { Feather M0 } \\
\text { (Adafruit) }\end{array}$ & $\begin{array}{l}\mathrm{PM}_{2.5}, \mathrm{PM}_{10}, \mathrm{CO}, \mathrm{CO}_{2}, \text { Sicaklık } \\
\text { Işk, Nem, Ses, }\end{array}$ & Kablolu & I2C/UART & $\sqrt{ }$ & $\begin{array}{l}\text { OLED } \\
\text { Display }\end{array}$ \\
\hline [19] & $\begin{array}{l}\text { Arduino } \\
\text { UNO }\end{array}$ & Sıcaklık, Bağıl Nem, CO2, Işık, Rüzgâr Hızı & IoT & ZigBee & $\sqrt{ }$ & Mobil \\
\hline [20] & $\begin{array}{l}\text { ARM / STM } \\
\text { 32F103VET6 }\end{array}$ & Rüzgâr Hızı, Sıcaklık, Nem, PM2.5, Mesafe & IoT & Wi-Fi & $\sqrt{ }$ & $\begin{array}{l}\text { LCD } \\
\text { Display }\end{array}$ \\
\hline [21] & $\begin{array}{l}\text { ARM / STM } \\
\text { 32F103C8T6 }\end{array}$ & Toz, Sicaklık, Nem, $\mathrm{CO}_{2}, \mathrm{PM}_{2.5}$, Formaldehit & IoT & $\begin{array}{l}\text { Çoklu } \\
\text { Kablosuz }\end{array}$ & $\mathrm{X}$ & Web/Mobil \\
\hline
\end{tabular}




\begin{tabular}{|c|c|c|}
\hline & $\begin{array}{l}\text { BŞEÜ Fen Bilimleri Dergisi } \\
7(1), 370-381,2020\end{array}$ & $\begin{array}{r}\text { BSEU Journal of Science } \\
\text { DOI: } 10.35193 / \text { bseufbd.730919 }\end{array}$ \\
\hline & & 58-7575 (http://dergipark.gov.tr/bseufbd) \\
\hline
\end{tabular}

\section{IAQ İZLEME SİSTEMININ TASARIMI}

Çalışma kapsamında geliştirilen IoT tabanlı IAQ izleme sisteminin çalışma prensibi, Şekil 1'de verilmiştir. Sistem içerisinde Raspberry Pi 3 kontrol kartı, sıcaklık ve nem sensörü, $\mathrm{CO}$, gaz sensörü ve ışık sensörü kullanılmıştır. Sistemin çalışma prensibine bakıldığında, ilk aşamada ortam ile ilgili veriler sensörler aracılığıyla ham olarak alınmaktadır. Ham sensör değerleri, Raspberry Pi 3 kontrol kartı aracılığıyla işlenerek ortam koşulları ile ilgili parametre değerleri elde edilmektedir. İkinci aşamada, parametre verileri veri tabanına kaydedilmekte ve web arayüzü aracılı̆̆ıla değerler çekilmektedir. Web arayüzüne çekilen veriler, sayısal ve grafiksel olarak kullanıcılara aktarılmaktadır. Sistem içerisinde sensör verilerini almak ve veri tabanına kaydetmek için Python, web arayüzü için ise PHP ve HTML programlama dilleri kullanılmıştır. Arayüz üzerinden ortam parametrelerine ek olarak iç ortamdaki hava kalitesinin sayısal değeri de kullanıcılara aktarılmaktadır.

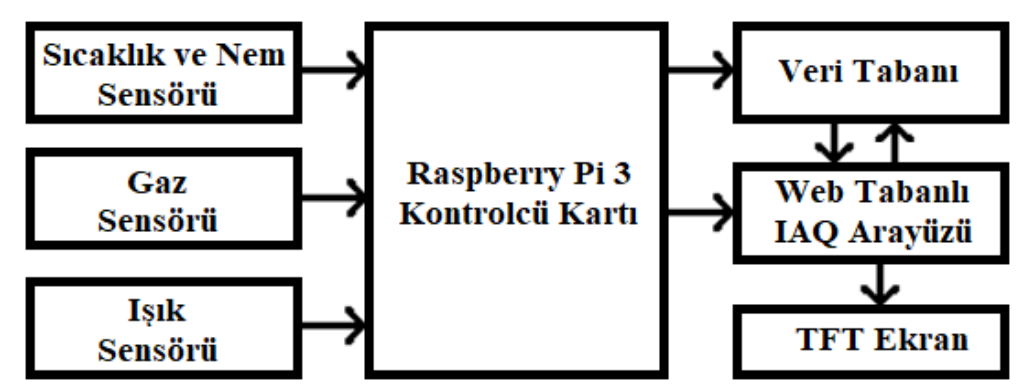

Şekil 1. IAQ izleme sisteminin çalışma prensibi

\section{A. Raspberry Pi 3 Tek Kartlı Bilgisayar}

Birleşik Krallık'ta bulunan ve kar amacı gütmeyen Raspberry Pi Vakfı tarafından geliştirilen Raspberry Pi kartları, düşük maliyetli ve kredi kartı büyüklüguündeki bilgisayarlar olarak 2009 yılında piyasaya sürülmüşlerdir. Üzerlerinde bulunan genel amaçlı giriş çıkış pinleri sayesinde, elektronik kart özelliğine sahip olmakta ve programlama yeteneği kazanmaktadır. Çalışmalara kapsamında, Raspberry Pi 3 kontrolcü kartı kullanılmıştır. İçerisinde, ARM tabanlı Cortex A53 işlemcisi, 1 GB RAM, microSD kart yuvaları, kamera arayüzü, HDMI girişi, $2.4 \mathrm{GHz}$ kablosuz internet, bluetooth ve GPIO pinleri gibi çevre elemanları bulunmaktadır. GPIO pinleri sayesinde UART, I2C, SPI vb. seri iletişim protokollerinin yanı sıra sensör kullanımına da imkân sağlamaktadır [22]. Linux ve Windows tabanlı işletim sistemleri ile çalışan bu kart, modüler olarak programlanabilir ve yönetilebilir bir bilgisayardır. Çalışma kapsamında, Raspbian işletim sistemi kullanılmıştır. Raspberry Pi 3 kartı, GPIO modülü üzerinden sensör kontrolünün kolay olması, web erişimi için harici donanım ya da modül gerektirmemesi, çalışmada kullanılan web arayüzü ve veri tabanı bileşenlerinin bütünleşik olarak kullanımı gibi avantajlarından ötürü tercih edilmiştir.

\section{B. IAQ Algilama Birimi}

Algılama birimi, iç ortamdaki hava kalitesini izlemek için kullanılan 3 sensörden (DHT11 Sıcaklık ve Nem Sensörü, MQ2 Gaz Sensörü, LDR sensörü) oluşmaktadır. DHT11 sensörü, iç ve dış ortamlardaki sıcaklık ve nem verilerinin ölçülmesi amacıyla kullanılan ve dijital olarak çıkış veren 4 pinli bir sensördür. İçerisindeki NTC birimi ile sıcaklığı, nem ölçüm birimi ile nemi ölçmektedir [23]. Şekil 2.a' da DHT11 sıcaklık ve nem sensörü verilmiştir. MQ2 gaz sensörü, iç ortamlarda bulunan bütan, metan, alkol, hidrojen, duman propanı gibi farklı gaz türlerini tespit etmek için kullanılan bir sensördür. Sensör, son derece hassastır ve tepki süresi çok hızlıdır. Analog olarak çıkış veren 4 pinli bir sensördür [24]. Şekil 2.b' de, MQ2 gaz sensörü verilmiştir. LDR sensörleri, 1şığa duyarlı olarak çalışan ve yarı iletken malzemelerden yapılmış sensörlerdir ve foto iletkenlik ilkesine bağlı olarak çalışmaktadırlar. Güneş 1şıkları, iletken malzemenin üzerine düştüğünde, serbest olan elektronların yer değiştirmesiyle LDR direncinde değişiklikler meydana gelmektedir. Bu değişen direnç değerleri ile bir çıkış değeri verirler. Analog ya da dijital olarak çıkış veren 2 pinli bir sensördür [25]. Şekil 2.c' de LDR ışık sensörü gösterilmiştir. Tablo 2'de, iç ortam parametrelerinin ölçümünde kullanılan sensörlere ait çalışma voltajları ve ölçüm aralıkları verilmiştir. 


\begin{tabular}{|c|c|c|}
\hline & $\begin{array}{l}\text { BŞEÜ Fen Bilimleri Dergisi } \\
7(1), 370-381,2020\end{array}$ & $\begin{array}{r}\text { BSEU Journal of Science } \\
\text { DOI: } 10.35193 / \text { bseufbd.730919 }\end{array}$ \\
\hline ERS & & 58-7575 (http://dergipark.gov.tr/bseufbd) \\
\hline
\end{tabular}

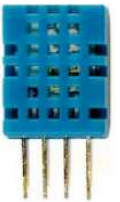

(a)

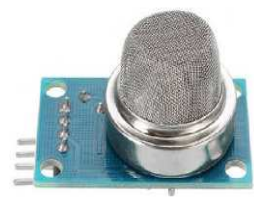

(b)

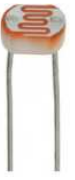

(c)

Şekil 2. Sensörler (a. DHT11 sensörü, b. MQ2 sensörü c. LDR sensörü)

Tablo 2. İç ortam ölçüm parametreleri

\begin{tabular}{ccc}
\hline Parametre & Çalışma Voltajı & Ölçüm Aralığı \\
\hline Sıcaklık [23] & $3-5.5 \mathrm{~V}$ & $0-50{ }^{\circ} \mathrm{C}$ \\
Nem [23] & $3-5.5 \mathrm{~V}$ & $\% 20-90 \mathrm{RH}$ \\
CO Gazı [26] & $5 \mathrm{~V}$ & $100-10000 \mathrm{ppm}$ \\
Duman [26] & $5 \mathrm{~V}$ & $100-10000 \mathrm{ppm}$ \\
Işı [27] & $5 \mathrm{~V}$ & $10-1000 \mathrm{lux}$ \\
\hline
\end{tabular}

\section{Veri Tabanı Tasarımı}

Çalışma kapsamında sensörlerden elde edilen ortam kalitesi parametrelerinin depolanması, gerçek zamanlı olarak işlenmesi ve web arayüzü üzerinden izlenebilmesi amacıyla bir veri tabanı tasarlanmıştır. Veri tabanı işlemleri için MySQL veri tabanı kullanılmıştır. Raspberry Pi 3 kartı içerisindeki Raspbian işletim sistemine kurulan MySQL sunucusu aracılığıyla çalıştırılan veri tabanına, sensörlerden alınan sıcaklık, nem, ışık şiddeti, duman ve CO gazı değerlerine ek olarak güncel zaman bilgisi de kaydedilmektedir. Veri tabanına kaydedilen parametre değerleri, web servisleri aracılığıyla arayüze aktarılmaktadır. Veri tabanı içerisindeki iç ortam parametreleri, yazılan servis uygulamaları ile web tabanlı kullanıcı arayüzüne aktarılmaktadır.

\section{Kullanıcı Arayüzü Tasarımı}

İç ortamdaki hava kalitesi değerlerinin kullanıcılara gerçek zamanlı olarak aktarılması amacıyla web tabanlı arayüz gerçekleştirilmiştir. IAQ izlem sistemine ait web arayüzü Şekil 3'de sunulmuştur. Geliştirilen arayüz, web ortamında gerçekleştirilmesiyle, kullanıcılara mobil cihazlar ve bilgisayarlar üzerinden ulaşabilecekleri genel bir erişim imkânı sunulmuştur. Arayüzün çalışma prensibi şu şekildedir. Sensörlerden alınarak veri tabanına kaydedilen parametre değerleri, web arayüzü için yazılan servis uygulaması aracılığıyla veri tabanından ayrı ayrı çekilmektedir. Arayüz içerisinde ortama ait her parametre değeri için grafikler oluşturulmakta ve genel hava kalitesine erişim sağlanmaktadır. Arayüz içerisinde ortama ait son değerlere doğrudan erişim varken, tüm verilere ulaşabilme imkânı da bulunmaktadır. Ortamdaki sıcaklık, nem, 1şık, duman ve CO gazı gibi parametreler için Highchart interaktif JavaScript kütüphaneleri kullanılarak grafiksel ekranlar oluşturulmuştur.

IC ORTAM HAVA KALITESI IZLEME ISTASYONU

\begin{tabular}{|c|c|c|c|c|c|c|c|}
\hline BIRIMLER & ZAMAN & $\begin{array}{c}\text { SICAKLIK } \\
\left({ }^{\circ} \mathrm{C}\right)\end{array}$ & $\begin{array}{c}\text { NEM } \\
(\%)\end{array}$ & $\begin{array}{c}\text { ISIK } \\
\text { (LUX) }\end{array}$ & $\begin{array}{c}\text { CO } \\
\text { (PPM) }\end{array}$ & $\begin{array}{c}\text { DUMAN } \\
\text { (PPM) }\end{array}$ & $\begin{array}{c}\text { GENEL HAVA } \\
\text { KALITESI (\%) }\end{array}$ \\
\hline $\begin{array}{c}\text { Guncel } \\
\text { Degerler }\end{array}$ & $\begin{array}{c}2019-07-06 \\
18: 51: 53\end{array}$ & 28 & 54 & 147 & 0.015 & 0.049 & 94.9 \\
\hline
\end{tabular}

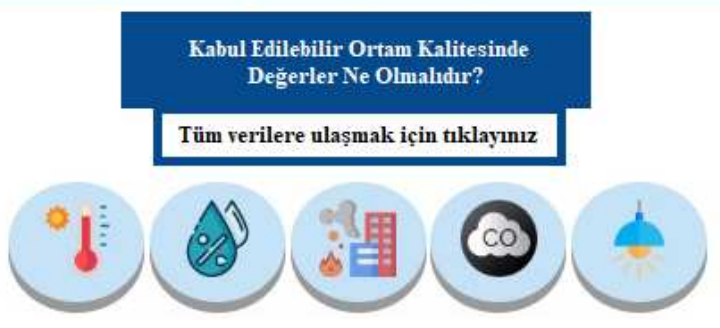

Şekil 3. İç ortam hava kalitesi web arayüzü 


\begin{tabular}{|c|c|c|}
\hline & $\begin{array}{l}\text { BŞEÜ Fen Bilimleri Dergisi } \\
7(1), 370-381,2020\end{array}$ & $\begin{array}{r}\text { BSEU Journal of Science } \\
\text { DOI: 10.35193/bseufbd.730919 }\end{array}$ \\
\hline & & 88-7575 (http://dergipark.gov.tr/bseufbd) \\
\hline
\end{tabular}

\section{IAQ İZLEME SISTTEMININ ÇALIŞMA YÖNTEMI}

İç ortamlardaki hava kalitesinin izlenmesi amacıyla geliştirilen sistemin blok diyagramı Şekil 4'te verilmiştir. Sistem içerisindeki sensörlerden alınan analog ve dijital değerler Raspberry Pi kontrol kartı içerisinde dönüşüm işlemlerine tabi tutularak ortam ile ilgili parametre değerleri elde edilmektedir. Elde edilen parametre değerleri, veri tabanına aktarılmaktadır. Geliştirilen kullanıcı arayüzü aracılığıyla veri tabanındaki değerler çekilmekte ve grafiksel olarak kullanıcılara aktarılmaktadır. Geliştirilen sistem ile ortam verileri anlık olarak takip edilebilmektedir.

Sistemde donanım olarak Raspberry Pi 3 kontrol kartı, MQ2 gaz sensörü, ADC click kartı, DHT11 sıcaklık ve nem sensörü ve LDR sensörü kullanılırken, yazılım olarak Python, HTML, PHP ve JavaScript dilleri kullanılmıştır. Raspberry Pi 3 kartında analog dijital dönüştürücü birimi olmadığından MQ2 gaz sensöründen alınan analog değerleri okumak için ADC click kartı kullanılmıştır. Kart üzerinde 4 adet ADC kanalı bulunmaktadır. Bunlardan birincisine MQ2 gaz sensörü bağlanıp ilgili kanaldan analog verilerin okunması sağlanmıştır. Raspberry Pi ile ADC click kartı arasındaki iletişim ise SPI seri haberleşme protokolü üzerinden gerçekleştirilmektedir. Sensörler ile Raspberry Pi 3 kartı arasındaki pin bağlantıları Tablo 3'de verilmiştir

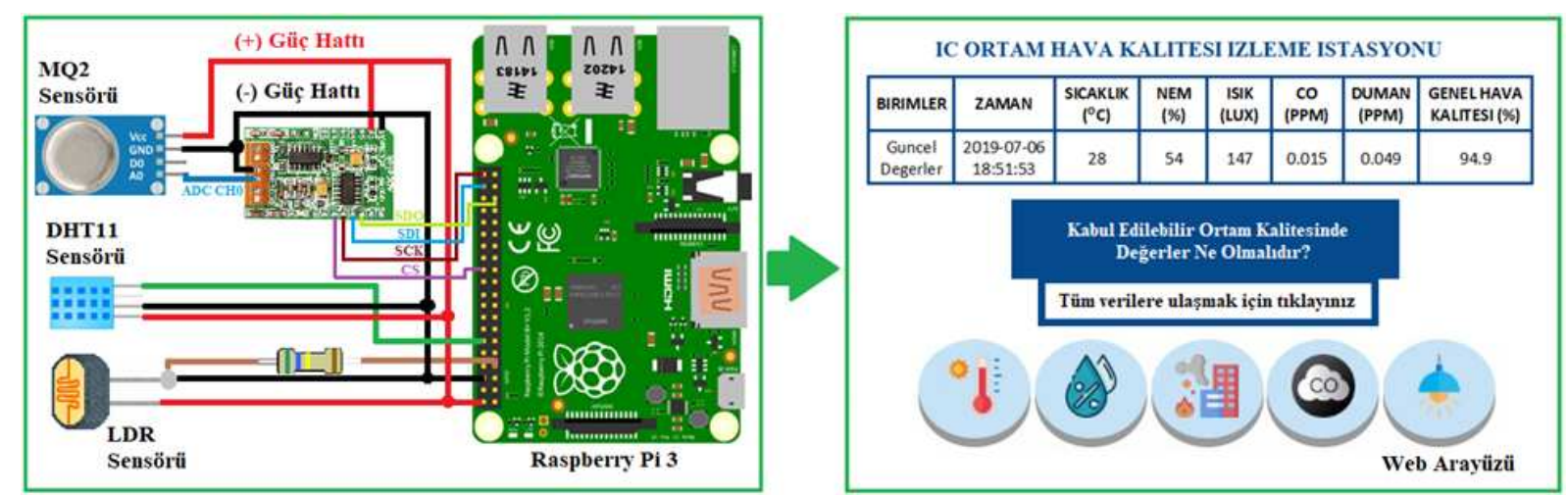

Şekil 4. IAQ izleme sisteminin blok diyagramı

Tablo 3. Pin Bağlantıları

\begin{tabular}{cc}
\hline Raspberry Pi 3 & Sensörler \\
\hline BCM4 & LDR \\
BCM18 & DHT11 \\
BCM19 & (ADC Click) SDO \\
BCM20 & (ADC Click) SDI \\
BCM21 & (ADC Click) SCK \\
BCM8 & (ADC Click) CS \\
\hline
\end{tabular}

\section{A. Hava Kalitesi Formülü}

IAQ'nin belirlenmesi için, çalışma kapsamında bir hava kalitesi formülü oluşturulmuş ve sensörlerden elde edilen parametre değerleri formülde kullanılarak iç ortamdaki hava kalitesinin oranı hesaplanmıştır. Her bir iç ortam parametresi için literatürde yer alan standartlara göre bir eşik seviyesi belirlenmiştir. Literatür taramaları sonucunda, eşik seviyelerini belirlerken ortam parametrelerinin insan sağlığı üzerindeki etkisine ve değerlerinin insanlar için önem durumuna bakılmışıır [28]. Parametrelerin kullanımına örnek olarak seçilen sıcaklık parametresi için Şekil 5'de gösterildiği gibi $0^{\circ} \mathrm{C}-50^{\circ} \mathrm{C}$ arasındaki değer aralıkları ele alınmıştır. EN ISO 7730' e göre IAQ açısından ortam sıcaklığının $20-26^{\circ} \mathrm{C}$ ve nemin $\% 30-70$ arasında olması gerekmektedir [28]. Buna uygun olarak çalışmada, en uygun sıcaklık değeri olarak $25^{\circ} \mathrm{C}$ seçilmiştir. Bu sıcaklık değerinin altı veya üstü uygunsuzluk seviyesine gitmektedir. 


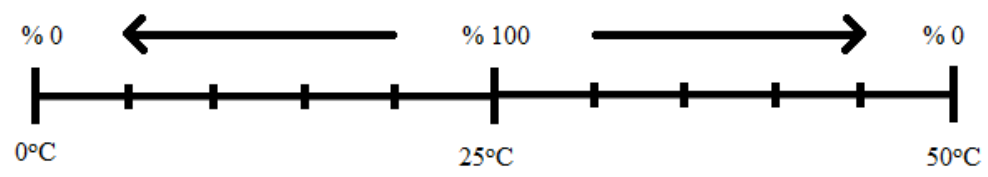

Şekil 5. Sıcaklık Parametresinin Yüzdelik Kalite Aralığı

Sıcaklık sensörünün kaba kodu Şekil 6'da verilmiştir. Şekilde sıcaklık değeri için optimum değer olarak $25^{\circ} \mathrm{C}$ seçilmiştir. Sıcaklığın verimi ile ilgili üç farklı yüzdelik değer hesaplama işlemi yapılmıştır. Kaba kodda verilen işlemlerde, sıcaklık değerinin $25^{\circ} \mathrm{C}$ 'den küçük, $25^{\circ} \mathrm{C}$ 'e eşit ve $25^{\circ} \mathrm{C}$ 'den büyük olma durumları verilmiştir. $\mathrm{Bu}$ durumlara bağlı olarak yüzdelik değer hesaplanmaktadır. Ortamdaki sıcaklık değeri, $0^{\circ} \mathrm{C}$ ve $50^{\circ} \mathrm{C}$ değerlerine yaklaştıkça sıcaklığın yüzdelik verimi düşmektedir. Kaba kodun çalışmasına örnek vermek gerekirse, sicaklık sensöründen alınan değer $\mathbf{3 0}$ C olsun, sıcaklık değeri “sicaklikKalite $=(\mathbf{5 0}-$ sicaklik $)$ * 4;" formülünde yerine konularak “(50 - 30) * 4=80\%” şeklinde hesaplanacaktır. Diğer sensörler ilgili yapılan kalite hesaplamaları, yüzdelik aralıklarının seçimleri ve formülasyon işlemleri için aynı işlemler yapılmıştır.

Tablo 4'de sensörler ile ölçülen değer aralıkları, IAQ parametrelerinin ortam seviyeleri, sağlık riski seviyeleri ve çalışma kapsamında seçilen optimum değer aralıkları verilmiştir. İç ortamdaki hava kalitesinin formülasyon işlemleri yapılırken ortam parametrelerinin seviyeleri ve insan sağlığı üzerindeki risk seviyeleri göz önüne alınmıştır [18, 28, 29].

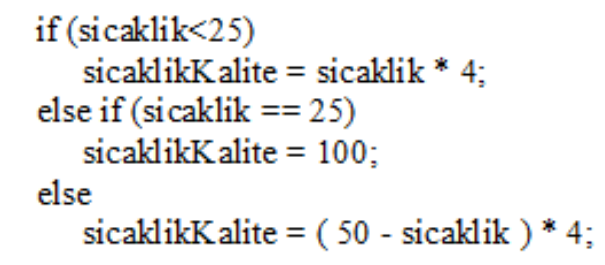

Şekil 6. Sıcaklık Sensörü için Geliştirilen Kaba Kod

Tüm sensörler için kalite değerleri hesaplandıktan sonra, genel ortam kalitesi değeri hesaplanmaktadır. Genel ortam kalitesi için kullanılan formül aşağıda verilmiştir. Her parametre için ortam değeri ve belirlenen eşik seviyeleri arasında kıyaslamalar yapılmış ve bu kıyaslamalar ile parametreler üzerinden kalite katsayıları hesaplanmıştır. Her sensör için belirlenen kalite katsayılarını kullanarak genel ortam kalitesi hesaplanmaktadır. Geliştirilen formüldeki “Ortalama” değeri, genel hava kalitesi temsil etmektedir.

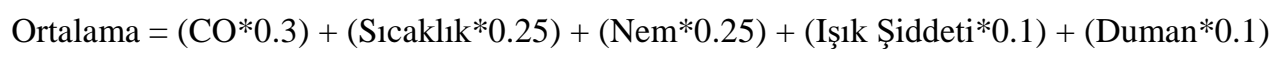

Tablo 4. Ortam Parametrelerinin Kalite Değerleri [18,28]

\begin{tabular}{ccccc}
\hline $\begin{array}{c}\text { IAQ } \\
\text { Parametreleri }\end{array}$ & $\begin{array}{c}\text { Ölçülen Değer } \\
\text { Aralıkları }\end{array}$ & $\begin{array}{c}\text { Ortam } \\
\text { Seviyeleri [18] }\end{array}$ & $\begin{array}{c}\text { Sağlık Riski } \\
\text { Seviyeleri }\end{array}$ & $\begin{array}{c}\text { Seçilen Değer } \\
\text { Aralıkları }\end{array}$ \\
\hline Sıcaklık & $0-50{ }^{\circ} \mathrm{C}$ & $16-26^{\circ} \mathrm{C}$ & $26>\mathrm{T}>20^{\circ} \mathrm{C}[28]$ & $20-25^{\circ} \mathrm{C}$ \\
Nem & $20-90 \%$ & $40-70 \%$ & $70>\mathrm{RH}>30 \%[28]$ & $40-70 \mathrm{RH}$ \\
Işı Şiddeti & $10-1000 \mathrm{lux}$ & $200-500 \mathrm{lux}$ & $<100 \mathrm{lux}[18]$ & $200-300 \mathrm{lux}$ \\
CO gazı & $100-10000 \mathrm{ppm}$ & $0-10 \mathrm{ppm}$ & $>10 \mathrm{ppm}[18]$ & $0-10 \mathrm{ppm}$ \\
Duman & $100-10000 \mathrm{ppm}$ & $0-10 \mathrm{ppm}$ & $>10 \mathrm{ppm} \mathrm{[29]}$ & $0-10 \mathrm{ppm}$ \\
\hline
\end{tabular}

\section{IAQ SİSTEMININ UYGULAMA TESTLERİ}

Geliştirilen IAQ istasyonunun donanımsal görünümü Şekil 7.a'da verilmiştir. İstasyon ile iç ortamdaki hava parametrelerinin hassas bir şekilde ölçülmesi ve işlenmesi sağlanmaktadır. Sensörler ile Raspberry Pi 3 kontrol kartı arasında, Tablo 2'de verilen GPIO pinleri üzerinden bağlantılar yapılmıştır. Web arayüzündeki 
verilerin anlık olarak izlenmesi ve takip edilmesi amacıyla istasyon üzerinde TFT ekran kullanılmıştır. Ekran sayesinde bütünleşik bir IAQ izleme sistemi geliştirilmiştir. Şekil 7.b'de istasyondaki TFT ekran üzerinden kullanıcılara gösterilen arayüz verilmiştir. Sensörlerden 5 saniyede bir alınan ortama ilişkin sıcaklık, nem, 1şık miktarı, duman ve CO gazı verileri veritabanına kaydedilmekte ve web arayüzü üzerinden kullanıcılara sunulmaktadır. Geliştirilen sistemin diğer sistemlere göre kolay kurulum, kablosuz teknolojinin kullanımı, TFT ekran sayesinde ayrı bir donanıma ihtiyaç duyulmadan ortamdaki hava kalitesi anlık olarak görülmesi, tek bir pencere arayüzünde tüm veri erişimi gibi avantajları bulunmaktadır.

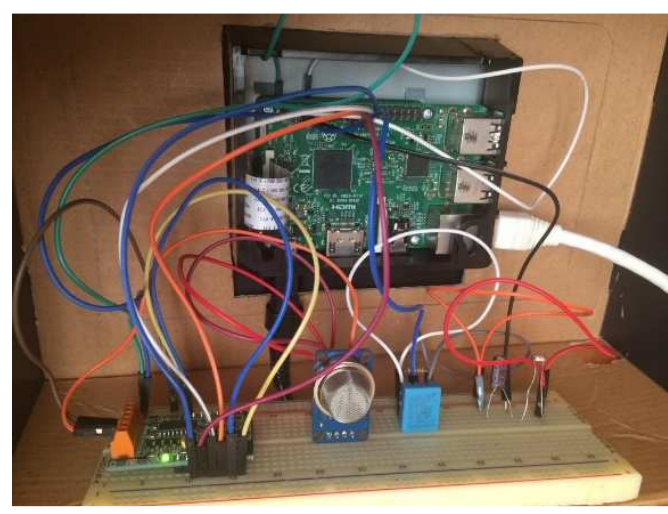

(a)

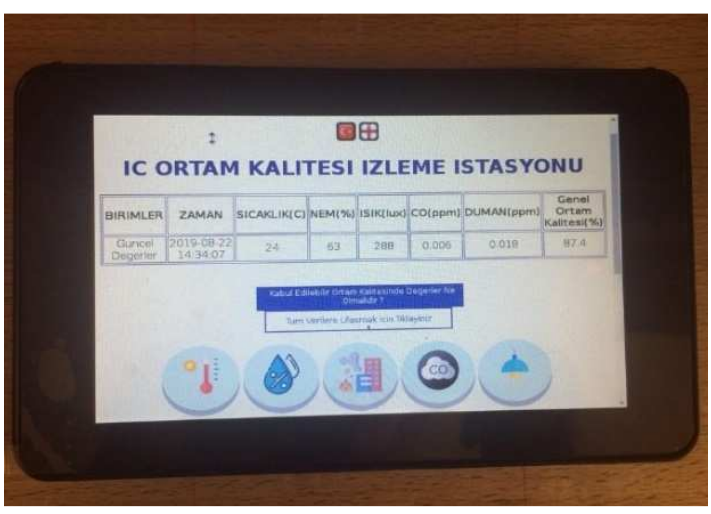

(b)

Şekil 7. (a) İstasyonunun donanımsal gösterimi, (b) TFT ekranda verilerin gösterimi

Şekil 8'de ortam parametrelerinin web arayüzü üzerinden grafiksel gösterimleri verilmiştir. Grafiklerde iteratif olarak gösterilen verilerde belirli aralıklarda artışların ve düşüşlerin yaşandığı görülmektedir. Bu sonuçlar, sensörlerden elde edilen verilere göre değişmektedir. Şekil 8'de sırasıyla (a) Sıcaklık, (b) Nem, (c) Işık Şiddeti, (d) Duman, (e) CO Gazı ve (f) Genel Ortam Kalitesi değerlerinin grafikleri verilmiştir. IAQ sistemi, laboratuvar ortamında yapılan deneylerle test edilmiştir. Grafiklerinin başlangıcında ortamdaki gaz seviyelerinin düşük olmasına bağlı olarak genel hava kalitesi oranının yüksek olduğu ve son kısımlara doğru seviyenin düştüğü görülmektedir. Bu durum sistemin, hava koşullarının değişimine karşın verilen hızlı tepkiyi göstermektedir. İlerleyen test çalışmalarında, iç ortamın sürekli izlenmesi ile daha kalıcı ve kontrollü bir sistem geliştirilecektir.

\section{SONUÇ VE DEĞERLENDİRME}

$\mathrm{Bu}$ çalışma kapsamında, IoT tabanlı IAQ izleme sistemi gerçekleştirilmiştir. Gerçekleştirilen izleme sisteminde temel amaç, IAQ’ni insan hayatı için en optimum seviyede tutulabilmek ve ortam koşullarından ötürü meydana gelebilecek olan sorunların üstesinden gelmektir. Bu amaca ulaşmak için kolay kurulum özelliğine sahip, düşük maliyetli ve kompakt bir donanım sistemi geliştirilmiştir. Sistem içerisinde Raspberry Pi 3 kontrolcü kartı, DHT11 sıcaklık ve nem sensörü, 1şık sensörü ve gaz sensörü kullanılmıştır. Bu sistem ile iç ortamdaki hava parametrelerinin (sıcaklık, nem, 1şık şiddeti, duman ve CO gazı) okunarak kullanıcılara görsel olarak aktarılması sağlanmaktadır.

Sensörlerden elde edilen ham veriler, Raspberry Pi 3 kontrolcü kartında işlendikten sonra MySQL veri tabanına kaydedilmiş, daha sonra iç ortamdaki hava kalitesini tespit etmek amacıyla geliştirilen formülde kullanılarak hava kalitesi hesaplanmıştır. Yazılan web servisi aracılığıyla veri tabanından çekilen ortam parametreleri, hazırlanan kullanıcı arayüzü üzerinden grafiksel ve sayısal olarak kullanıcılara aktarılmıştır. Önerilen sistem ile cihazın bulunduğu ortamdaki hava parametrelerinin uzaktan izlenilmesine imkân veren bir uygulama sunulmuştur.

Yapılan testler sonucunda elde edilen bilgilerin 1şı̆̆ında, gerçekleştirilen sistemin kabul edilebilir IAQ'nin sağlanması hususundaki katkısının umut verici olduğu görülmektedir. Gerçekleştirilen sistemin yerleştirileceği farklı ortamlara göre farklı performans göstermesi mümkün olacaktır. Örneğin, kapalı mekânlarda 


\begin{tabular}{|c|c|c|}
\hline & $\begin{array}{l}\text { BŞEÜ Fen Bilimleri Dergisi } \\
7(1), 370-381,2020\end{array}$ & $\begin{array}{r}\text { BSEU Journal of Science } \\
\text { DOI: } 10.35193 / \text { bseufbd.730919 }\end{array}$ \\
\hline ERS & & 58-7575 (http://dergipark.gov.tr/bseufbd) \\
\hline
\end{tabular}

çalışan işçi sağlığını korumak ve işçi performansını artırmak, özel ilgi ve bakım gerektiren hasta, yaşlı ve bebeklerin bulunduğu ortamların sağlığını ve konforunu korumak amacıyla kullanılabilecektir. İlerleyen çalışmalarda, daha geniş kapsamlı bir iç ortam izleme sisteminin kurulması ve sistemin yapay zekâ teknikleri ile desteklenerek akıllı hale getirilmesi planlanmaktadır.

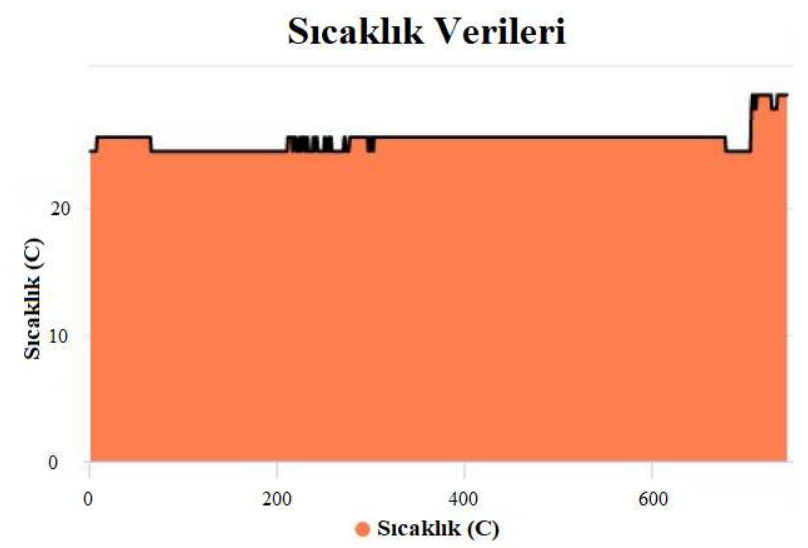

(a)

\section{Işık Şiddeti Verileri}

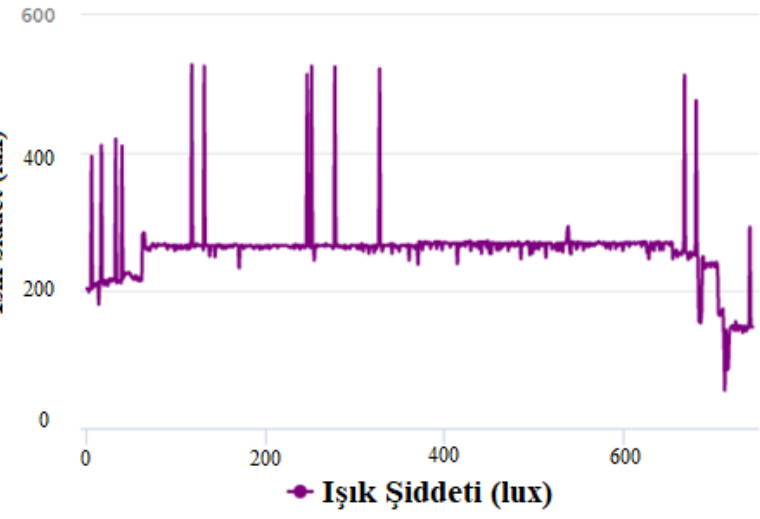

(c)

\section{CO Gazı Verileri}

0.15

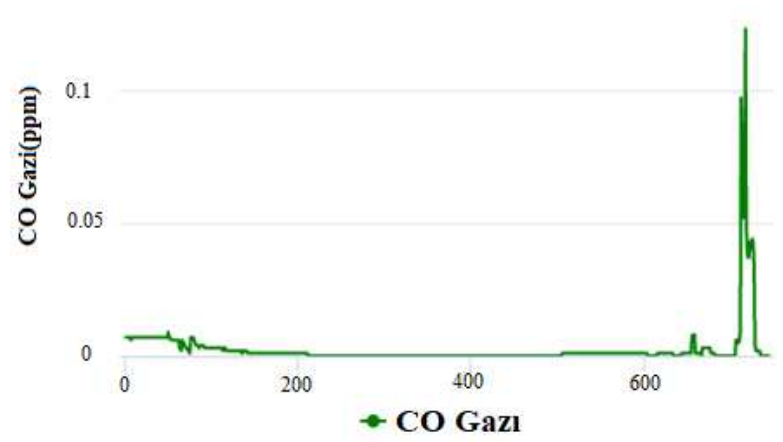

(e)

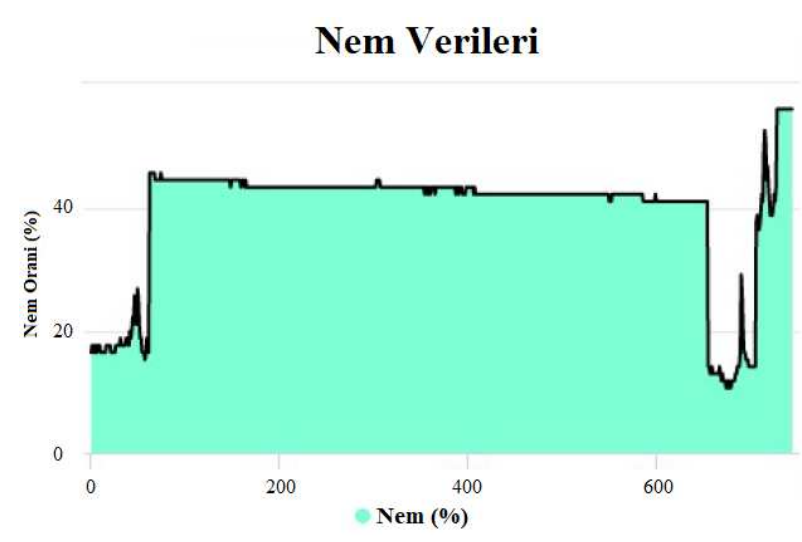

(b)

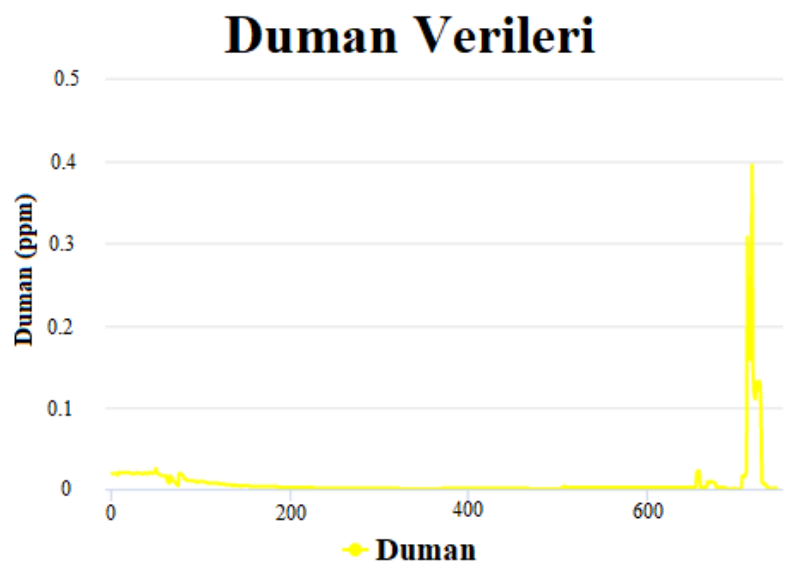

(d)

\section{Genel Ortam Kalitesi}

125

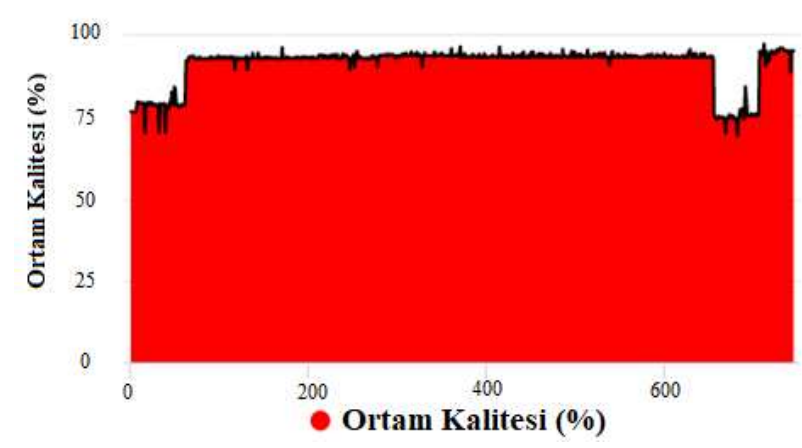

(f)

Şekil 8. Ortamdaki hava kalitesi parametrelerinin grafiksel gösterimleri

(a) Sıcaklık, (b) Nem, (c) Işık şiddeti, (d) Duman, (e) CO gazı, (f) Genel ortam kalitesi 


\section{KAYNAKLAR}

[1] Hammami, A. (2019). Smart Environment Data Monitoring. 2019 International Conference on Computer and Information Sciences (ICCIS), 3-4 April, Sakaka, Saudi Arabia, pp. 1-6.

[2] Majumder, A.J.A., Mcwhorter, T.M., Ni, Y., Nie, H., Iarve, J., Ucci, D.R. (2019). sEmoD: A Personalized Emotion Detection Using a Smart Holistic Embedded IoT System. 2019 IEEE 43rd Annual Computer Software and Applications Conference (COMPSAC), 15-19 July, Milwaukee, WI, USA, pp. 850-859.

[3] Shah J., Mishra, B. (2016). Customized IoT enabled wireless sensing and monitoring platform for smart buildings. Procedia Technology, 23, 256-263.

[4] Venkatanarayanan, A., Vijayavel, A., Rajagopal, A., Nagaradjane, P. (2019). Design of sensor system for air pollution and human vital monitoring for connected cyclists. IET Communications, 13(19), 3181-3186.

[5] Ghosh, R., Gardner, J.W., Guha, P.K. (2019). Air Pollution Monitoring Using Near Room Temperature Resistive Gas Sensors: A Review. IEEE Transactions on Electron Devices, 66(8), 3254-3264.

[6] Firdhous, M.F.M., Sudantha, B.H., Karunaratne, P.M. (2017). IoT enabled proactive indoor air quality monitoring system for sustainable health management. 2017 2nd International Conference on Computing and Communications Technologies (ICCCT), 23-24 February, Chennai, India, pp. 216-221.

[7] Pham, N.Q, Rachim, V.B., Chung, W.Y. (2018). EMI-Free Bidirectional Real-Time Indoor Environment Monitoring System. IEEE Access, 7, 5714-5722.

[8] Abraham, S., Li, X. (2014). A cost-effective wireless sensor network system for indoor air quality monitoring applications. [J]. Procedia Computer Science, 34, 165-171.

[9] Spiru, P., Simona, P.L. (2017). A review on interactions between energy performance of the buildings, outdoor air pollution and the indoor air quality. Energy Procedia, 128, 179-186.

[10] Başaran, D., Karanfil, B., Tüysüz, B. (2018). Çoklu modül destekli enerji etkin akıllı kontrol sistemi. Sakarya Üniversitesi Fen Bilimleri Enstitüsü Dergisi, 22(2), 468-479.

[11] Huang, K., Song, J., Feng, G., Chang, Q., Jiang, B., Wang, J., Sun, W., Li, H., Wang F., Fang, X. (2018). Indoor air quality analysis of residential buildings in northeast China based on field measurements and longtime monitoring. Building and Environment, 144, 171-183.

[12] Yalçın, N. (2017). Gaz Sensörleri ile Ölçüm Sistemleri için Ortam Modelleme ve Simülatör Geliştirilmesi. Doktora Tezi, Sakarya Üniversitesi Fen Bilimleri Enstitüsü, Sakarya.

[13] Quang Phuc Ha, Q.P., Metia, S., Phung, M.D. (2020). Sensing Data Fusion for Enhanced Indoor Air Quality Monitoring. IEEE Sensors Journal, 20(8), 4430-4441.

[14] Jo, J.H., Jo, B.W., Kim, J.H., Kim, S.J., Han, W.Y. (2020). Development of an IoT-Based Indoor Air Quality Monitoring Platform. Journal of Sensors, 2020, Article ID 8749764, 1-14.

[15] Le, H.A., Linh, V.T.Q. (2020). Investigation of Indoor and Outdoor Air Quality at Elementary Schools in Hanoi, Vietnam. VNU Journal of Science: Earth and Environmental Sciences, 36(1), 30-37.

[16] Marques, G., Ferreira C.R., Pitarma, R. (2019). Indoor Air Quality Assessment Using a CO2 Monitoring System Based on Internet of Things. Journal of Medical Systems, 43(67), 1-10.

[17] Sung, W.T., Hsiao, S.J., Shih, J.A. (2019). Construction of Indoor Thermal Comfort Environmental Monitoring System Based on the IoT Architecture. Journal of Sensors, 2019, Article ID 2639787, 1-16. 
[18] Tiele, A., Esfahani, S., Covington, J. (2018). Design and Development of a Low-Cost, Portable Monitoring Device for Indoor Environment Quality. Journal of Sensors, 2018, Article ID 5353816, 1-14.

[19] Salamone, F., Belussi, L., Danza, L., Ghellere, M., Meroni, I. (2015). Design and development of nEMoS, an all-in-one, low-cost, web connected and 3D-printed device for environmental analysis. Sensors, 15(6), 13012-13027.

[20] Zhao, Z., Wang, J., Fu, C., Liu, Z. Liu, D., Li, B. (2018). Design of a Smart Sensor Network System for RealTime Air Quality Monitoring on Green Roof. Journal of Sensors, 2018, Article ID 1987931, 1-13.

[21] Zhao, L., Wu, W., Li., S. (2019). Design and Implementation of an IoT-Based Indoor Air Quality Detector with Multiple Communication Interfaces. IEEE Internet of Things, 6(6), 9621-9632.

[22] Chen, P.H., Cross, N. (2018). IoT in Radiology: Using Raspberry Pi to Automatically Log Telephone Calls in the Reading Room. Journal of Digital Imaging, 31, 371-378.

[23] Divya, M., Subhash, N., Vishnu, P., Tejesh, P. (2020). Smart Health Care Monitoring Based on Internet of Things (IoT). International Journal of Scientific Research and Engineering Development, 3(1), 409 - 414.

[24] Nowshin, N., Mazumder, P., Soikot, M.A., Probal, M., Qadir, M.U. (2019). Designing and Implementation of Microcontroller Based Non-Invasive Health Monitoring System. 2019 International Conference on Robotics, Electrical and Signal Processing Techniques (ICREST), 10-12 January, Dhaka, Bangladesh, pp. 134-139.

[25] Dheena, P. P. F., Raj, G.S., Dutt, G., Jinny, S.V. (2017). IOT based smart street light management system. 2017 IEEE International Conference on Circuits and Systems (ICCS), 20-21 December, Thiruvananthapuram, India, pp. 368-371.

[26] Light Dependent Resistor Datasheet. (1997). http://www.bilimteknik.tubitak.gov.tr/sites/default/files/ gelisim/elektronik/dosyalar/40/LDR_NSL19_M51.pdf, (11.16.2020)

[27] Hanwei Electronics. (2020). Technical Data MQ-2 Gas Sensor Datasheet, http://www.haoyuelectronics.com/Attachment/MQ-2/MQ-2.pdf, (11.16.2020)

[28] Olesen, B.W. (2000). Guidelines for Comfort. ASHRAE Journal, 40-45.

[29] Perera, I. E., Litton, C. D. (2014). Evaluation of Smoke and Gas Sensor Responses for Fires of Common Mine Combustibles. Transactions of Society for Mining, Metallurgy, and Exploration, Inc, 336(1), 381-390. 